\title{
Photoperiod and Nitrogen Supply Limit the Scope of Northward Migration and Seed Transfer of Black Spruce in a Future Climate Associated with Doubled Atmospheric $\mathrm{CO}_{2}$ Concentration
}

\author{
Junlin Li', Qing-Lai Dang1*, Rongzhou Man² \\ ${ }^{1}$ Faculty of Natural Resources Management, Lakehead University, Thunder Bay, Canada \\ ${ }^{2}$ Ontario Ministry of Natural Resources, Ontario Forest Research Institute, Sault Ste. Marie, Canada \\ Email: "qdang@lakeheadu.ca
}

Received 25 November 2014; accepted 18 January 2015; published 20 January 2015

Copyright ( 2015 by authors and Scientific Research Publishing Inc.

This work is licensed under the Creative Commons Attribution International License (CC BY).

http://creativecommons.org/licenses/by/4.0/

(c) (i) Open Access

\section{Abstract}

The predicated changes in precipitation and temperature associated with the continued elevation of atmospheric $\mathrm{CO}_{2}$ concentration will trigger the northward shift of the Climate Envelopes for 130 North America tree species by as much as 10 degrees. However, climate envelope models do not take into account changes in other factors that may also influence the survival and growth of plants at the predicted new locations, such as photoperiod and nutrient regimes. This study investigated how photoperiod and nitrogen supply would affect the ecophysiological traits of black spruce (Picea mariana (Mill) B. S. P.) that are critical for survival and growth at new locations predicted by climate envelope models. We exposed black spruce seedlings to the photoperiod regime at the seed origin (PS) and that $10^{\circ}$ north of the seed origin (PNM) as predicted by climate envelope models under the current and doubled atmospheric $\mathrm{CO}_{2}$ concentration and different levels of $\mathrm{N}$ supply (30 vs. $300 \mu \mathrm{mol} \cdot \mathrm{mol}^{-1} \mathrm{~N}$ ). We found that the PNM and the $30 \mu \mathrm{mol} \cdot \mathrm{mol}^{-1} \mathrm{~N}$ supply both had negative impact on the development of seedling cold hardiness in the fall, and led to earlier burst of the terminal bud and greater rate of mortality in the following growing season. While the PNM stimulated seedling growth in the first growing season, the effect was not sustained in the second growing season. Our results suggest that the photoperiod regimes and poor nutrient conditions at higher latitudes will likely constrain the scope of the northward migration or seed transfer of black spruce.

\section{Keywords}

Plant Migration, Tree Seed Transfer, Nutrient, Cold Hardiness, Picea mariana (Mill) B.S.P., Boreal "Corresponding author. 


\section{Forest, Climate Envelope}

\section{Introduction}

As global warming continues [1], the temperature and precipitation regimes further north may become more suitable for boreal trees [2]-[4]. Northern America is one of the regions with the most pronounced increases in temperature [5] [6]. Based on the projections of temperature and precipitation by the Atmosphere Ocean General Circulation Models, the climate envelopes for 130 North American tree species will shift northward by as much as 10 degrees (about 1100 kilometers) by 2071 to 2100. However, a successful migration or seed transfer of a species may also be influenced by other ecological and environmental factors, such as photoperiod and nutrient supply [7] [8]. For example, a change in photoperiod regime can change the timing of phenological events [9] and a change in nutrient supply may affect survival and growth [10]. It is unknown how changes in photoperiod and nutrient supply may affect the migration or seed transfer of boreal tree species.

Changes in photoperiod regimes can induce anomalies in phenological events which in turn affect the survival and growth of plants at their new locations. For example, a delayed onset and a lower degree of cold hardening may expose plants to freeze damages in the winter and earlier bud bursts will expose plants to the risk of frost damage in the spring [11]. The ability to develop adequate cold hardiness is critical for the survival of plants in regions with cold winters [12] [13]. Cold hardiness affects not only plant survival in the winter, but also growth in the next growing season because the formation and size of terminal buds as well as the timing of bud burst are closely related to cold hardiness [14]. Although longer summer photoperiods and longer growing seasons at higher latitudes can increase plant growth [15], the shorter days in the winter and shorter duration of dormancy may affect the growth in the next growing season. A good understanding of the interactive effects of photoperiod, temperature and $\mathrm{CO}_{2}$ elevations on plant physiology thus may be pivotal for predicting the likelihood of success in plant migration and seed transfer under the predicted future climate conditions.

The growth of forests at high latitudes is limited by the availability of nitrogen (N) [16]. Although ecosystems at high latitudes can store large amounts of nutrient in the soil, the available $\mathrm{N}$ is lower further north due to the lower rates of decomposition and mineralization of organic materials [17]. The predicted $2^{\circ} \mathrm{C}-4^{\circ} \mathrm{C}$ increase in mean summer temperature does not necessarily translate into a corresponding increase in available $\mathrm{N}$ because of interactions among, air temperature, soil temperature, moisture, and soil microorganisms that are adapted to low temperatures [18]. Although low $\mathrm{N}$ supplies generally help cold hardening [19], a certain amount of $\mathrm{N}$ is required for the proper development of cold hardiness and other physiological functions [20]. Currently, there are conflicting results in the literature on the relationship between cold hardiness and $\mathrm{N}$ supply [21]. Although the effects of $\mathrm{CO}_{2}$ elevation and nutrient availability on plant physiology and morphology have been studied relatively extensively [22] [23], the potential impact of changes in $\mathrm{N}$ supply and photoperiod on the northward migration or seed transfer of boreal tree species is poorly understood.

Black spruce is a key tree species in the Canadian boreal forests. It is sensitive to photoperiod [24] and adapted to the photoperiod regimes of its current habitats [9]. For example, its terminal bud formation cannot be initiated by low air temperatures unless accompanied by either a short photoperiod or a low nitrogen supply [25]. Therefore, black spruce is an excellent species to use for studying the interactive effects of $\mathrm{CO}_{2}$, photoperiod and nitrogen supply on the migration and seed transfer of boreal trees in the context described previously. In this study, we exposed black spruce seedlings to the photoperiod regime of the seed origin and that at $10^{\circ}$ north of the seed origin (based on the prediction by Climate Envelope models [26]) under two nitrogen supplies (low vs. high) and two $\mathrm{CO}_{2}$ concentrations (current vs. doubled). We hypothesize that the photoperiod regime at the higher latitude and the low $\mathrm{N}$ supply would adversely affect the development of cold hardiness and advance the timing of bud burst in the following growing season.

\section{Materials and Methods}

\subsection{Plant Materials}

Black spruce (Picea mariana [Mill.] B.S.P.) seeds were collected from a 64 year-old black spruce stand near 
Huntsville, Ontario, Canada ( $45^{\circ} 26^{\prime} 49.54^{\prime \prime} \mathrm{N}, 79^{\circ} 14^{\prime} 35.15^{\prime \prime}$, elevation $\left.281.9 \mathrm{~m}\right)$. The stand was composed of 70\% black spruce, 20\% balsam fir (Abies balsamea (L.) Mill., and 10\% larch Larix laricina (Du Roi) K. Koch) in a lowland riparian zone near Lake Fish. The soil of the stand was organic layers overlain on mineral with rich nutrient contents. The moisture regime was generally very moist to wet. Daily average air temperatures range from $-10.3^{\circ} \mathrm{C}$ (January) to $18.7^{\circ} \mathrm{C}$ (July). Mean annual precipitation is $1105.1 \mathrm{~mm}(832.2 \mathrm{~mm}$ rain and $338 \mathrm{~cm}$ snow fall). About 5000 (about 0.1 pound) seeds were collected from 30 trees at least $50 \mathrm{~m}$ apart from each other. The seeds were germinated in the greenhouse. 480 germinants were chosen randomly and transplanted into pots (15 cm tall, $13 \mathrm{~cm}$ top diameter). The growing medium was a mixture of peat moss and vermiculite $(1 / 1 \mathrm{v} / \mathrm{v})$.

\subsection{Experiment Design and Treatments}

The treatments consisted of two $\mathrm{CO}_{2}$ concentrations ( $370 \mathrm{vs.} 720 \mu \mathrm{mol} \cdot \mathrm{mol}^{-1}$ ), two photoperiod regimes (photoperiod at seed origin: PS; photoperiod at $10^{\circ}$ north of seed origin: PNM) and two levels of nitrogen supply (30 vs. $300 \mu \mathrm{mol} \cdot \mathrm{mol}^{-1} \mathrm{~N}$ ).). The photoperiods for PS were 15 and $10 \mathrm{~h}$ for active growing and cold hardening phase, respectively and the respective photoperiods for the PNM treatment were 17 and $8 \mathrm{~h}$. The 15-hour photoperiod represents the actual median photoperiod during the growing season at the seed origin and the 17-hour is the corresponding median photoperiod $10^{\circ}$ north from the seed origin (Figure 1). The 10 and 8 hour photoperiods represent the median photoperiods during cold hardening phase for the above two locations. $60 \mu \mathrm{mol} \cdot \mathrm{mol}^{-1} \mathrm{P}$

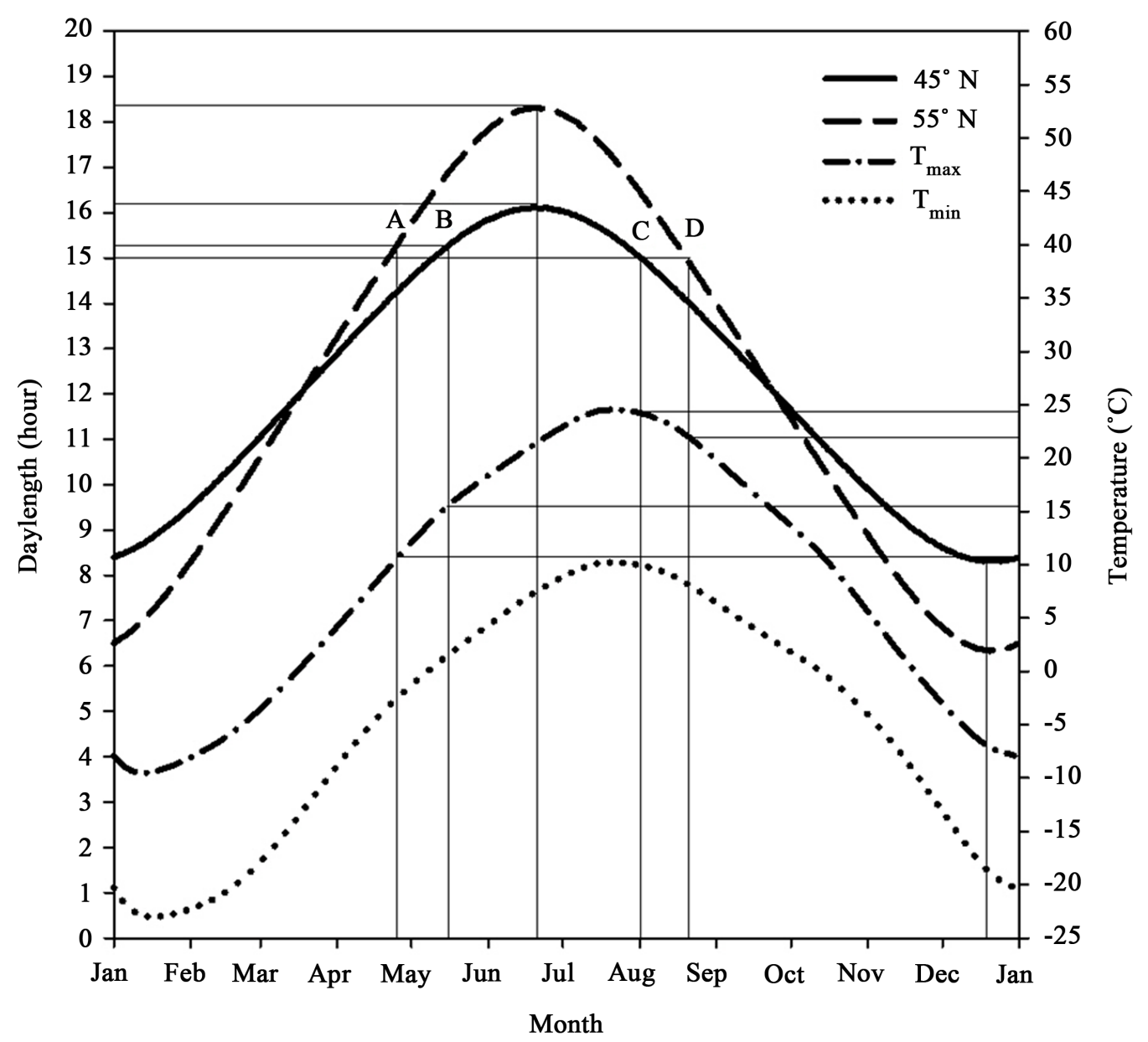

Figure 1. Schematic diagram of daylength and air temperature at $45^{\circ}$ (seed origin) and $55^{\circ} \mathrm{N}$ latitude $\left(10^{\circ}\right.$ north from seed origin). Points A and B indicate the critical daylength for bud burst at the two locations while points $\mathrm{C}$ and $\mathrm{D}$ represent the critical daylength for bud set. $\mathrm{T}_{\max }$ and $\mathrm{T}_{\min }$ are monthly maximum and minimum air temperatures at the location of seed origin (Data source: U.S. Naval Observatory (Astronomical Applications Department, 2009) and World Clim (Hijmans et al., 2005). 
and $150 \mu \mathrm{mol} \cdot \mathrm{mol}^{-1} \mathrm{~K}$ were used in both $\mathrm{N}$ treatments. $\mathrm{N}, \mathrm{P}$ and $\mathrm{K}$ were formulated using ammonium nitrate $\left(\mathrm{NH}_{4} \mathrm{NO}_{3}\right)$, super phosphate $\left(\mathrm{P}_{2} \mathrm{O}_{5}\right)$, and muriate of potash $\left(\mathrm{K}_{2} \mathrm{O}\right)$. The high $\mathrm{N}$ concentration and the concentrations of $\mathrm{P}$ and $\mathrm{K}$ are the optimal levels for the growth of black spruce seedlings (Landis 1989). The experiment was carried out in four greenhouses with identical design features and control devices. Each of the two $\mathrm{CO}_{2}$ treatments was randomly assigned to two greenhouses. Since the natural day length was shorter than the required photoperiods (started in September), the natural photoperiod was extended using high pressure sodium lamps which gave about $600 \mu \mathrm{mol} \cdot \mathrm{m}^{-1} \cdot \mathrm{s}^{-1}$ flux density of photosynthetically active radiation at the canopy level.

The $\left[\mathrm{CO}_{2}\right]$, photoperiod, temperature and humidity were automatically controlled and monitored using an Argus control system (Argus Control Systems Ltd, Vancouver, BC, Canada). The same temperature regime $\left(25^{\circ} \mathrm{C}-26^{\circ} \mathrm{C} / 16^{\circ} \mathrm{C}-17^{\circ} \mathrm{C}\right.$ day/night temperature) was used for both PS and PNM treatments because according to the theory of climate envelope the temperature and moisture regimes define the climate envelope and would remain the same after the climate envelope shifts to a new location [2] [3]. The photoperiods in all the greenhouses were set to the value for the PNM and the shorter photoperiod for the PS was achieved by shading the seedlings at both ends of the day. The photoperiod treatments were started with the values for the active growing phase (15 hours for 75 days for PS and 17 hours for 95 days for PNM) and followed by the corresponding values for cold hardening (10 hours for 50 days for PS and 8 hours for 30 days for PNM). The photoperiod and temperature regimes (Figure 1) were determined according to the Astronomical Applications Department (2009) [27] and Hijmans et al. (2005) [28]. The seedlings were fertilized once a week. The water content of the growing medium was maintained above $30 \%$ as determined using an $\mathrm{HH} 2$ Moisture Meter (Delta-T Devices, Cambridge, U.K.). The seedlings were watered to the dripping point when the volumetric water content of the growing medium declined to $30 \%$ [29].

\subsection{Measurements}

After 125-days of treatments (Growth Cycle I), height, root collar diameter, terminal bud size, biomass, chlorophyll fluorescence and cold hardiness were measured on seedlings randomly selected from each treatment combination (30 seedlings for height, root collar diameter and terminal bud size, 3 for biomass, 10 for chlorophyll fluorescence, and 15 for cold hardiness). Stem volume (V) was calculated from height (H) and RCD (D) according to van den Driessche (1992): $\mathrm{V}=\left(\pi \mathrm{D}^{2} / 4\right) \mathrm{H} / 3$. Biomass was determined separately for shoots and roots after oven-drying at $75^{\circ} \mathrm{C}$ for 48 hours in order to calculate root mass ratio (RMR = root mass/total seedling mass).

Chlorophyll fluorescence was measured on the terminal shoot using an FMS 2 pulse modulated chlorophyll fluorometer following a 30 min dark adaptation (Hansatech Instruments Ltd, Norfolk, England). The maximum quantum efficiency of Photosystem II was derived from the initial (Fo) and maximum (Fm) fluorescence (Fv/Fm $=(\mathrm{Fm}-\mathrm{Fo}) / \mathrm{Fm})$. The length and width of the terminal bud were determined using an AMS-MV2 high-resolution digital imaging system (Advanced Microscopy Group, Mill Creek, WA, USA, 2008) and Micron Imaging Software (USB2) 1.08 (Westover Scientific, Inc., Mill Creek, WA, USA, 2008).

The cold hardiness was assessed according to Colombo et al. [30] [31]. 2 - $3 \mathrm{~cm}$ long shoot tips were cut and rinsed with distilled water. Three tips were used for each of the following test temperatures: control (no freezing), $-5^{\circ} \mathrm{C},-15^{\circ} \mathrm{C},-30^{\circ} \mathrm{C}$ and $-60^{\circ} \mathrm{C}$. Each tip was placed in a separate jar filled with $100 \mathrm{ml}$ distilled water and incubated at room temperature $\left(20^{\circ} \mathrm{C}-25^{\circ} \mathrm{C}\right)$ for 24 hours. The electrical conductivity of the solution was measured (referred to as ECC) using an Accumet AR 20 electrical conductivity meter (Fisher Scientific, Ottawa, Canada). Each test temperature was achieved using a programmable freezer (Foster Refrigeration Ltd, King's Lynn Norfolk, U. K.) by reducing the temperature at a rate of $5^{\circ} \mathrm{C} / \mathrm{h}$. One hour after the testing temperature was reached, the temperature was increased back to the room temperature at a rate of $5^{\circ} \mathrm{C} / \mathrm{h}$ and the electric conductivity of the solution was again measured (referred to as ECF). Subsequently the jars were placed in an oven at $80^{\circ} \mathrm{C}$ for two hours. After cooling to the room temperature overnight, the electric conductivity of the solution was measured again (referred to as ECK). The injury index $\left(I_{i}\right)$, which is inversely related to the cold hardiness, was calculated according to Colombo et al. [30] (1984) and Colombo [31] (2003) as follows:

$$
I_{i}=\frac{\frac{E C F}{E C K}-\frac{E C C}{E C K}}{1-\frac{E C C}{E C K}} \times 100
$$


At the completion of all the measurements, all remaining seedlings were cold-stored $\left(-4^{\circ} \mathrm{C}\right)$ for three months for the second growth cycle. The second growth cycle was aimed to examine the treatment effects on bud phenology and seedling survival and growth in the next growing season. The seedlings were exposed to the same growth conditions as in Growth Cycle I. The seedlings in the PS treatment were exposed to short photoperiod (10 hours) for three weeks and then to the long photoperiod (15 hours) for six weeks while the seedlings in the PNM treatment were first exposed to the corresponding short photoperiod (8 hours) for one week and then to the corresponding long photoperiod (17 hours) for eight weeks. The earlier start of the long photoperiod in the PNM treatment was dictated by the faster rate of change in photoperiod at the higher latitude (Figure 1). The bud phenology was observed daily. The total number of days in the long photoperiod regime to bud burst (DBBL) were recorded. Height and RCD were measured again at the end of the second growth cycle. The relative growth rates of height $\left(R_{G R}\right)$, RCD $\left(R_{G R}\right)$ and volume $\left(R_{G R}\right)$ were determined by dividing the growth increments in the second growth cycle by the corresponding measurements at the end of the first growth cycle.

\subsection{Statistical Analysis}

The experiment was a split-plot design with $\mathrm{CO}_{2}$ treatment as the main plot and factorial combinations of photoperiod and nutrient supply as the split plot. The data were examined graphically for normality (probability plots for residuals) and homogeneity of variance (scatter plots). Both assumptions for the analysis of variance (ANOVA) were satisfied. When ANOVA showed a significant interaction $(P \leq 0.05)$, the Least Significant Difference (LSD) multiple comparisons were conducted. Since all the seedlings in the low $\mathrm{N}$ treatment died in the $2^{\text {nd }}$ growth cycle, the nitrogen treatment was not included in the analysis for growth cycle II. All the analyses were conducted using the GenStat statistics package, 12th Edition (VSN international Ltd, Hemel Hempstead, UK, 2009).

\section{Results}

\subsection{Morphology and Biomass}

$\mathrm{N}$ supply significantly affected the responses of seedling height, RCD, biomass and biomass allocation to roots to photoperiod and $\left[\mathrm{CO}_{2}\right]\left(\mathrm{N} \times \mathrm{P}, \mathrm{N} \times \mathrm{C}\right.$ and $\mathrm{N} \times \mathrm{P} \times \mathrm{C}$ in Table 1). While the $\mathrm{CO}_{2}$ elevation and PNM both increased height and RCD growth, the increases were greater in the high than low $\mathrm{N}$ supply (Figure 2). In fact, the increases in RCD were not statistically significant in the low N treatment (Figure 2(c) and Figure 2(d)). The PNM also resulted in a greater increase in seedling biomass in the high than in the low $\mathrm{N}$ supply (Figure 3(b)).

Table 1. $\mathrm{P}$ values for treatment effects of $\mathrm{CO}_{2}$ concentration $\left(\mathrm{C}, 370\right.$ and $\left.720 \mu \mathrm{mol} \cdot \mathrm{mol}^{-1}\right)$, photoperiod $(\mathrm{P}$, seed origin and $10^{\circ}$ north), nutrient supply (N, 30 and $300 \mu \mathrm{mol} \cdot \mathrm{mol}^{-1} \mathrm{~N}$ ) and their interactions on height (H), root collar diameter (RCD), bud length (BL), bud width (BW), root mass ratio (RMR), total biomass (TM), index of injury (Ii) (at test temperatures of $-5^{\circ} \mathrm{C},-15^{\circ} \mathrm{C},-30^{\circ} \mathrm{C}$, and $\left.-60^{\circ} \mathrm{C}\right)$, and maximum quantum efficiency of PSII $\left(\mathrm{F}_{\mathrm{v}} / \mathrm{F}_{\mathrm{m}}\right)$ of black spruce seedlings after for 125 days of growth (Growing season I).

\begin{tabular}{|c|c|c|c|c|c|c|c|}
\hline \multirow{2}{*}{ Source of variation } & \multicolumn{7}{|c|}{ Treatment effects } \\
\hline & $\mathrm{C}$ & $\mathrm{P}$ & $\mathrm{N}$ & $\mathrm{C} \times \mathrm{P}$ & $\mathrm{C} \times \mathrm{N}$ & $\mathrm{P} \times \mathrm{N}$ & $\mathrm{C} \times \mathrm{P} \times \mathrm{N}$ \\
\hline $\mathrm{H}$ & 0.035 & 0.015 & $<0.001$ & 0.564 & 0.002 & 0.005 & 0.659 \\
\hline RCD & 0.115 & 0.062 & $<0.001$ & 0.981 & $<0.001$ & $<0.001$ & 0.206 \\
\hline BL & 0.097 & 0.049 & $<0.001$ & 0.134 & 0.403 & 0.002 & 0.652 \\
\hline BW & 0.37 & 0.137 & 0.002 & 0.173 & 0.268 & 0.002 & 0.383 \\
\hline RMR & 0.239 & 0.012 & $<0.001$ & 0.889 & 0.005 & 0.718 & 0.02 \\
\hline TM & 0.527 & 0.114 & $<0.001$ & 0.806 & 0.107 & 0.05 & 0.115 \\
\hline $\mathrm{F}_{\mathrm{v}} / \mathrm{F}_{\mathrm{m}}$ & 0.097 & 0.275 & $<0.001$ & 0.479 & 0.249 & $<0.001$ & 0.851 \\
\hline $\mathrm{Ii}\left(-5^{\circ} \mathrm{C}\right)$ & 0.904 & 0.08 & 0.002 & 0.379 & 0.161 & 0.802 & 0.709 \\
\hline Ii $\left(-15^{\circ} \mathrm{C}\right)$ & 0.072 & 0.043 & $<0.001$ & 0.871 & 0.008 & 0.034 & 0.754 \\
\hline Ii $\left(-30^{\circ} \mathrm{C}\right)$ & 0.057 & $<0.001$ & $<0.001$ & 0.038 & 0.246 & 0.022 & 0.946 \\
\hline Ii $\left(-60^{\circ} \mathrm{C}\right)$ & 0.071 & 0.626 & $<0.001$ & 0.867 & 0.494 & 0.128 & 0.124 \\
\hline
\end{tabular}




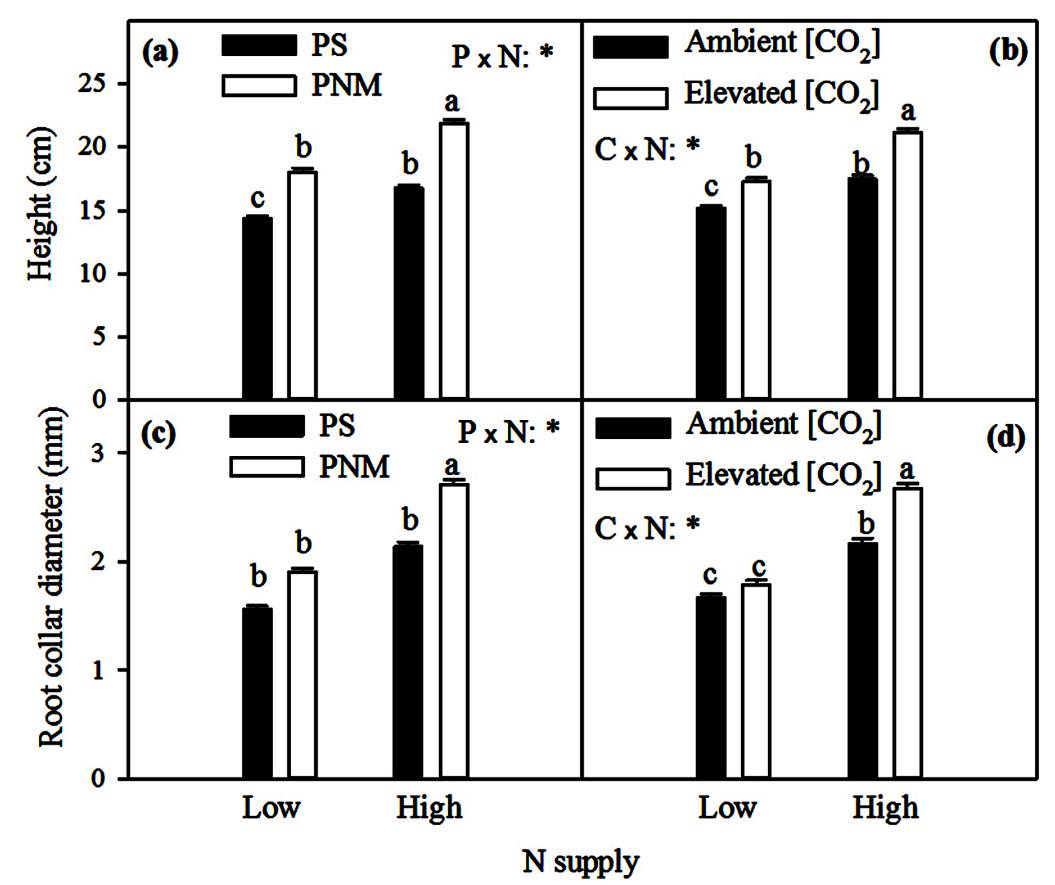

Figure 2. Mean (+SEM) height (a and b) and root collar diameter (c and d) of black spruce seedlings after 125 days of growth under two $\left[\mathrm{CO}_{2}\right]$ (C) levels (370 (ambient) vs. 720 (elevated) $\mu \mathrm{mol} \cdot \mathrm{mol}^{-1} \mathrm{CO}_{2}$ ), two photoperiods (P) (PS - seed origin and PNM-10 north of seed origin), and two nutrient supply ( $\mathrm{N}$ ) levels (30 (Low) vs. 300 (High) $\left.\mu \mathrm{mol} \cdot \mathrm{mol}^{-1} \mathrm{~N}\right)$. “"” indicates significant effects $(\mathrm{P} \leq 0.05)$. Means with different letters were significantly different from each other $(\mathrm{P} \leq 0.05)$.
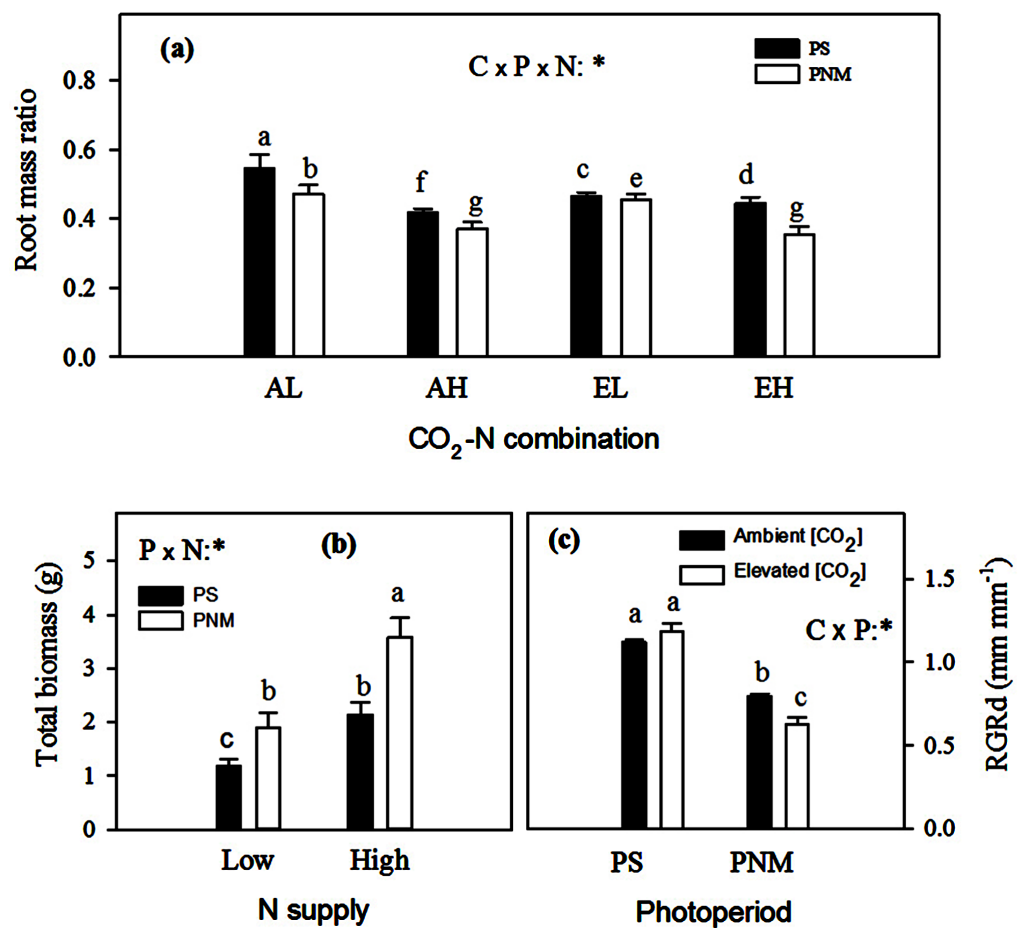

Figure 3. Mean (+SEM) root mass ratio and total seedling biomass in black spruce. "AL" represents for the treatment combination of "ambient $\left[\mathrm{CO}_{2}\right] \times$ low $\mathrm{N}$ supply", "AH" for "ambient $\left[\mathrm{CO}_{2}\right] \times$ high $\mathrm{N}$ supply", "EL" for "elevated $\left[\mathrm{CO}_{2}\right] \times$ low N supply", and "EH" for "elevated $\left[\mathrm{CO}_{2}\right] \times$ high $\mathrm{N}$ supply". See Figure 2 for other explanations. 
The $\mathrm{CO}_{2}$ elevation decreased the root mass ratio in the low $\mathrm{N}$ supply in both photoperiod treatments but increased RMR under the high N supply and PS (Figure 3(a)). While the PNM generally decreased RMR, there were significant interactions with $\mathrm{CO}_{2}$ and $\mathrm{N}$ : the photoperiod impact was greater in the low than the high $\mathrm{N}$ treatment under the ambient $\left[\mathrm{CO}_{2}\right]$ but the trend was the opposite under the elevated $\left[\mathrm{CO}_{2}\right]$, i.e., the impact was greater in the high than the low $\mathrm{N}$ treatment (Figure 3(a)).

All the seedlings in the low $\mathrm{N}$ treatment died in the second growth cycle and thus $\mathrm{N}$ supply was not considered in the second growth cycle. While the positive effect of PNM on height growth remained significant (30.47 \pm 1.40 vs. $26.49 \pm 1.03 \mathrm{~cm}$, Table 2) in the second growth cycle, the effects of PNM and $\left[\mathrm{CO}_{2}\right]$ on RCD became insignificant (Table 2). The relative growth rates of height, stem volume and RCD, however, showed opposite trends to those of height and RCD growth, i.e., PNM reduced the RGR for height ( $0.44 \pm 0.01$ for PNM vs. $0.59 \pm 0.01 \mathrm{~cm} \cdot \mathrm{cm}^{-1}$ for PS), stem volume (3.23 \pm 0.15 vs. $6.39 \pm 0.22 \mathrm{~cm}^{3} \cdot \mathrm{cm}^{-3}$ ) and RCD (Figure $3(\mathrm{c}$ )). The $\mathrm{CO}_{2}$ elevation also significantly reduced the RGR of RCD under the PNM but did not affect it under the PS (Table 2 and Figure 3(c)). Photoperiod also had no significant effects on height increment (Hi) or RCD increment (RCDi) in the second growth cycle. No treatment had a significant effect on total seedling biomass in the second growth cycle (Table 2).

\subsection{Bud Size, Chlorophyll Fluorescence and Cold Hardiness}

Buds were much longer and wider under the PS than PNM photoperiod regime in the high $\mathrm{N}$ treatment, but photoperiod had no significant effect on bud size in the low $\mathrm{N}$ treatment (Table 1 and Figure 4). The elevated $\left[\mathrm{CO}_{2}\right]$ also did not significantly affect bud size (Table 1 ).

In the first growth cycle, the maximum quantum efficiency of PSII $\left(\mathrm{F}_{\mathrm{v}} / \mathrm{F}_{\mathrm{m}}\right)$ was greater in the high than low $\mathrm{N}$ treatment in both photoperiod treatments, and the PNM significantly increased $\mathrm{F}_{\mathrm{v}} / \mathrm{F}_{\mathrm{m}}$ only at the high $\mathrm{N}(\mathrm{P} \times \mathrm{N}$ interaction in Table 1, Figure 5(a)). In the following growth cycle, the PNM significantly increased $F_{v} / F_{m}$ under the elevated $\left[\mathrm{CO}_{2}\right]$, and the $\mathrm{CO}_{2}$ elevation increased $\mathrm{F}_{\mathrm{v}} / \mathrm{F}_{\mathrm{m}}$ in both photoperiod treatments $(\mathrm{C} \times \mathrm{P}$ interaction in Table 2, Figure 5(b)).

Table 2. $\mathrm{P}$ values for treatments effects of $\mathrm{CO}_{2}$ concentration $\left(\mathrm{C}, 370\right.$ and $\left.720 \mu \mathrm{mol} \cdot \mathrm{mol}^{-1}\right)$, photoperiod $(\mathrm{P}$, seed origin and $10^{\circ}$ north), and their interactions on height $(\mathrm{H})$, root collar diameter $(\mathrm{RCD})$, height increment $\left(\mathrm{H}_{\mathrm{i}}\right)$, RCD increment $\left(\mathrm{RCD} \mathrm{D}_{\mathrm{i}}\right)$, relative growth rates of height $\left(R_{G R}\right)$, root collar diameter $\left(R_{G R}\right)$ and volume $\left(R_{G R}\right)$, root mass ratio $(R M R)$, total biomass (TM), number of long days to bud burst (DBBL), mortality, and maximum quantum efficiency of PSII photochemistry $\left(\mathrm{F}_{\mathrm{v}} / \mathrm{F}_{\mathrm{m}}\right)$ of black spruce seedlings after 63 days of growth in the Growing season II. The level of nutrient supply was dropped due to seedlings mortality after cold storage.

\begin{tabular}{|c|c|c|c|}
\hline \multirow{2}{*}{ Source of variation } & \multicolumn{3}{|c|}{ Treatment effects } \\
\hline & $\mathrm{C}$ & $P$ & $\mathrm{C} \times \mathrm{P}$ \\
\hline $\mathrm{H}$ & 0.056 & 0.029 & 0.221 \\
\hline RCD & 0.112 & 0.483 & 0.896 \\
\hline $\mathrm{Hi}$ & 0.076 & 0.382 & 0.896 \\
\hline RCDi & 0.277 & 0.368 & 0.407 \\
\hline RGRh & 0.157 & 0.018 & 0.486 \\
\hline RGRd & 0.14 & 0.003 & 0.042 \\
\hline RGRv & 0.278 & 0.005 & 0.081 \\
\hline RMR & 0.532 & 0.057 & 0.173 \\
\hline $\mathrm{TM}$ & 0.393 & 0.124 & 0.777 \\
\hline DBBL & 0.332 & 0.947 & 0.567 \\
\hline $\mathrm{F}_{\mathrm{v}} / \mathrm{F}_{\mathrm{m}}$ & 0.011 & 0.032 & 0.053 \\
\hline Mortality & 0.795 & 0.012 & 0.423 \\
\hline
\end{tabular}




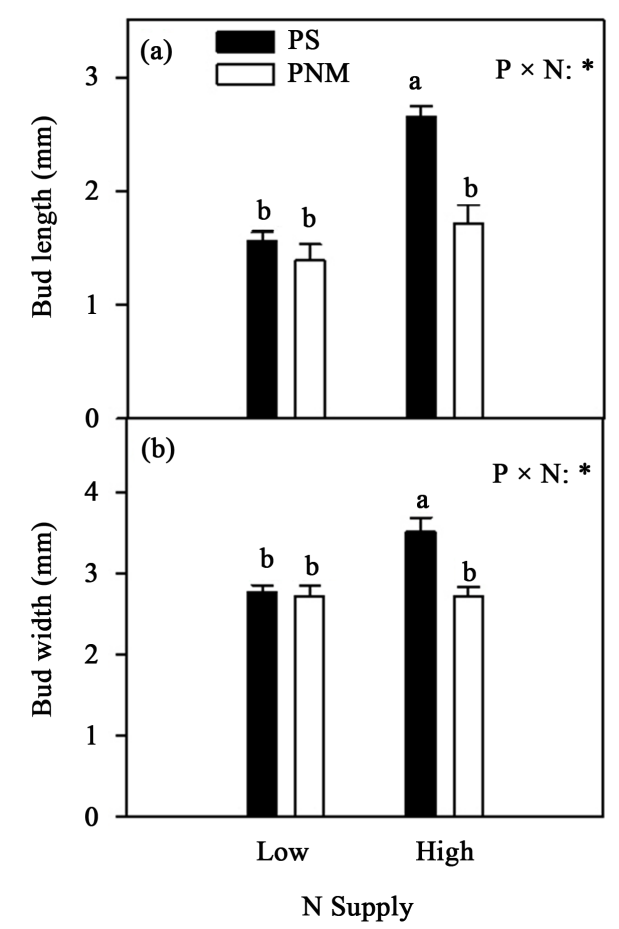

Figure 4. Mean (+SEM) bud length and bud width in black spruce seedlings. See Figure 2 for other explanations.
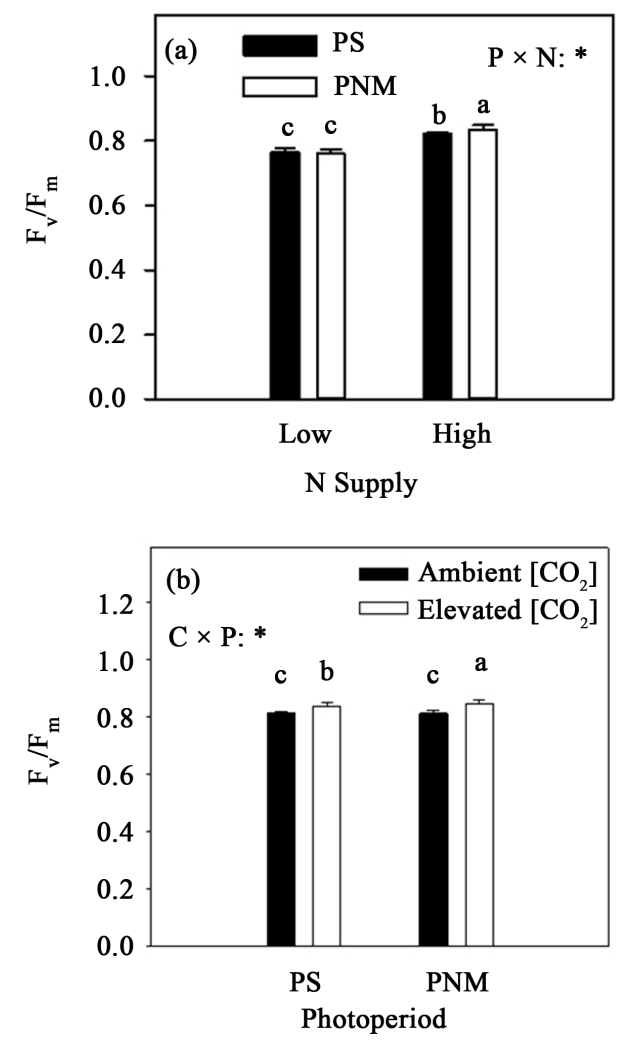

Figure 5. Mean (+SEM) maximum quantum efficiency of PSII $\left(F_{v} / F_{m}\right)$ of black spruce seedlings measured in the first (a) and second growth cycle (b). See Figure 2 for other explanations. 
The freezing injury was generally much greater in the low than high $\mathrm{N}$ treatment at all the freezing temperatures $\left(-5^{\circ} \mathrm{C}\right.$ to $-60^{\circ} \mathrm{C}$, Table 1). For example, the injury index at $-5^{\circ} \mathrm{C}$ was $4.20 \pm 0.34$ (mean $\pm \mathrm{SEM}$ ) and 2.87 \pm 0.20 for the low and high $\mathrm{N}$ respectively, and $30.91 \pm 0.81$ and $15.15 \pm 0.89$ for the low and high $\mathrm{N}$ respectively at $-60^{\circ} \mathrm{C}$. $\mathrm{N}$ supply also significantly influenced the effects of $\left[\mathrm{CO}_{2}\right]$ and photoperiod on freezing injuries at the two modest freezing temperatures, $-15^{\circ} \mathrm{C}$ and $-30^{\circ} \mathrm{C}$ (Table 1). While the injury index was generally greater in the PNM than in the PS, the difference was greater in the high $\mathrm{N}$ treatment at $-15^{\circ} \mathrm{C}$ but trend was the reverse at $-30^{\circ} \mathrm{C}$ (Figure 6(a) \& Figure 6(c)). The $\mathrm{CO}_{2}$ elevation reduced the freezing injury in the low but not in the high $\mathrm{N}$ treatment (Figure 6(b)). The $\mathrm{CO}_{2}$ elevation increased freezing injury in both photoperiod treatments but the PNM increased freezing injury only under the ambient $\left[\mathrm{CO}_{2}\right]$ (Figure 6(d)).

\subsection{Mortality and DBBL}

Seedling mortality was greater in the PNM than the PS (Table 2; $41.46 \% \pm 4.81 \%$ vs. $4.17 \% \pm 0.41 \%$ ). None of the treatments had a significant effect on the timing of bud burst (DBBL in Table 2).

\section{Discussion}

Our data suggest that $\mathrm{CO}_{2}$ elevations, photoperiod regimes further north from the seed origin and high nitrogen supply will likely increase the growth of black spruce. The results are consistent with the findings of others that elevated $\mathrm{CO}_{2}$ alone [22] [32]-[35] or in combination with high nutrient supply [36] [37] enhances photosynthesis and promotes growth. The increased growth under the PNM was probably due to the longer photoperiod (17 h vs. $15 \mathrm{~h}$ ) during the longer growing season (95 days vs. 75 days, Figure 1). The growth stimulation by PNM was further enhanced by the high $\mathrm{N}$ supply. Lower biomass allocations to roots under certain conditions, such as less nutrient stress [38] or drought stress [39], also lead to greater aboveground growth, as evidenced by the enhanced seedling height and RCD in this study. The growth enhancement by the $\mathrm{CO}_{2}$ elevation or PNM, however, largely disappeared in the second growth cycle, resulting in lower relative growth rates. The reversal of growth enhancement in the second growth cycle may have been related to the poor quality of buds and inadequate development of cold hardiness. The shorter time period for cold hardening under the PNM may have been a contributing factor.

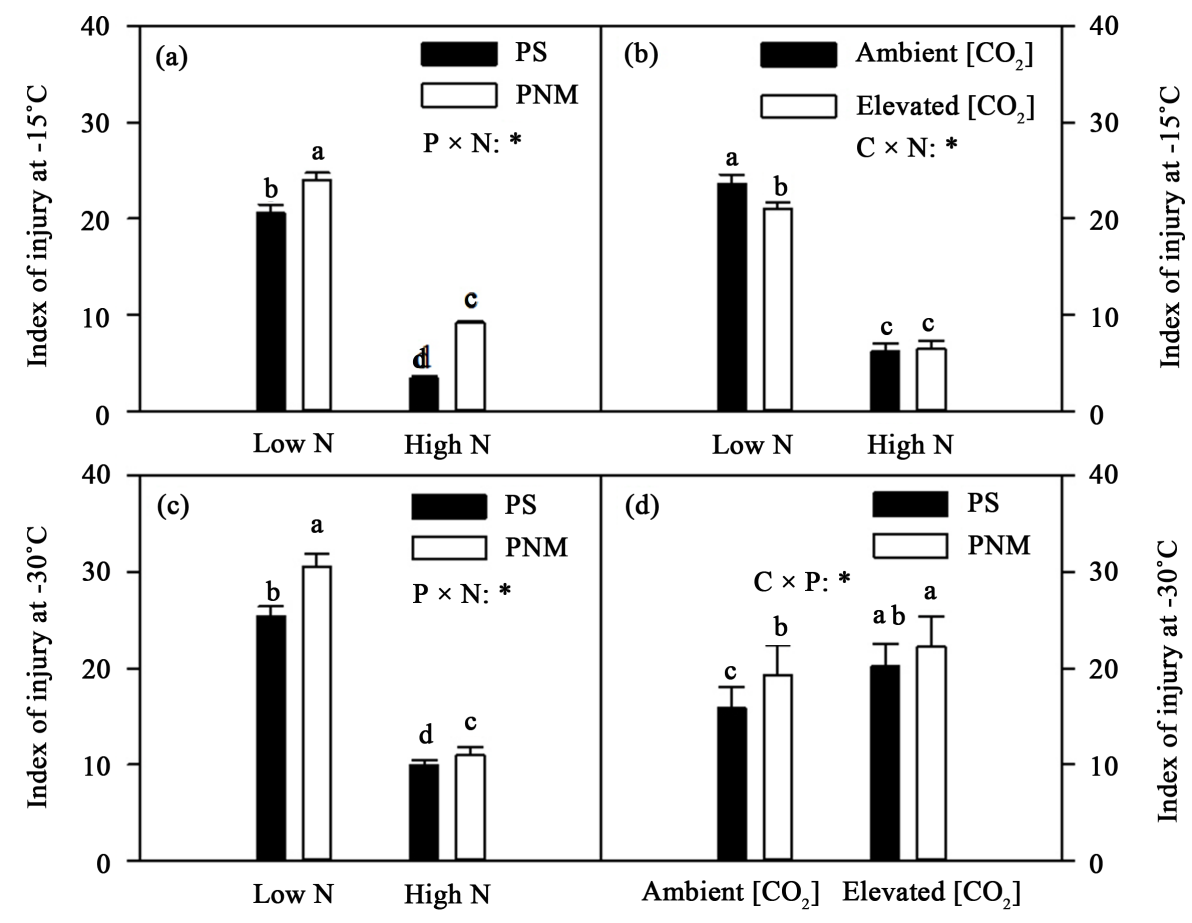

Figure 6. Mean (+SEM) injury index of black spruce seedlings measured at different freezing temperatures. See Figure 2 for other explanations. 
Our results suggest that the change in photoperiod regime associated with a northward migration will likely retard the development of adequate cold hardiness and thus limit the scope of such migrations or seed transfers. Black spruce is sensitive to changes in photoperiod [31] [40] and continues vegetative growth without setting buds under long days [41]. The longer growing season photoperiods north of the seed origin reduce the time period for the development of cold hardiness in the fall, leading to deteriorated cold hardiness and increased vulnerability to freezing injuries as indicated by the smaller bud size [42], higher $F_{v} / F_{m}$ and $F_{o}$ [22] [43] [44] and greater freezing injury index. Therefore, although the climate envelope for the species may shift to higher latitudes under the predicted scenario of climate change, a successful migration or seed transfer will depend on the ability of the specific genetic material to develop adequate cold hardiness in shortened periods of time for cold hardening with greater rates of temperature declining than their current habitats. This ecophysiological trait may be critical for the success of future tree breeding programs in forestry.

The results also demonstrate that an adequate nutrient supply is critical for the development of proper cold hardiness in black spruce. This finding is consistent with the results of other studies [20] [25] [45]. It is well known that too much nutrient supply, particularly nitrogen, has negative impact on the development of plant cold hardiness [19]. However, it is less well known that too little nutrient supply can also jeopardize the hardening in the fall [20]. The results of this study show that insufficient supply of nitrogen can jeopardize the proper hardening of black spruce and lead to severe freezing injuries and mortality in the following growing season. This suggests that low nutrient availability may also restrict the natural spread or introduction of black spruce to poor sites.

\section{Acknowledgements}

We thank Dr. C. Shahi for advice on statistics and J. Lee for greenhouse assistance. This study was supported by NSERC DG to Q.L. Dang.

\section{References}

[1] IPCC (2007) Climate Change 2007: The Physical Science Basis. Cambridge University Press, Cambridge.

[2] McKenney, Daniel W., Pedlar, J.H., Lawrence, K., Campbell, K. and Hutchinson, M.F. (2007) Potential Impacts of Climate Change on the Distribution of North American Trees. BioScience, 57, 939-948. http://dx.doi.org/10.1641/B571106

[3] McKenney, D.W., Pedlar, J.H., Rood, R.B. and Price, D. (2011) Revisiting Projected Shifts in the Climate Envelopes of North American Trees Using Updated General Circulation Models. Global Change Biology, 17, 2720-2730. http://dx.doi.org/10.1111/j.1365-2486.2011.02413.x

[4] Walther, G.R., Post, E., Convey, P., Menzel, A., Parmesan, C., Beebee, T.J.C., Fromentin, J.M., Hoegh-Guldberg, O. and Bairlein, F. (2002) Ecological Responses to Recent Climate Change. Nature, 416, 389-395. http://dx.doi.org/10.1038/416389a

[5] Bronson, D.R., Gower, S.T., Tanner, M. and Van Herk, I. (2009) Effect of Ecosystem Warming on Boreal Black Spruce Bud Burst and Shoot Growth. Global Change Biology, 15, 1534-1543. http://dx.doi.org/10.1111/j.1365-2486.2009.01845.x

[6] Hansen, J., Ruedy, R. and Sato, M. (1996) Global Surface Air Temperature in 1995: Return to Pre-Pinatubo Level. Geophysical Research Leiters, 23, 1665-1668. http://dx.doi.org/10.1029/96GL01040

[7] Chen, C., Hill, J.K., Ohlemuller, R., Roy, D.B. and Thomas, C.D. (2011) Rapid Range Shifts of Species Associated with High Levels of Climate Warming. Science, 333, 1024-1026. http://dx.doi.org/10.1126/science.1206432

[8] Pitelka, L.F. (1997) Plant Migration and Climate Change. American Scientist, 85, 464-473.

[9] Thomas, B. and Vince-Prue, D. (1997) Photoperiodism in Plants. Second Edition, Academic Press, London.

[10] Marschner, H. (1995) Mineral Nutrition of Higher Plants. Academic Press, San Diego.

[11] Man, R.Z., Kayahara, G.J., Dang, Q.L. and Rice, J.A. (2009) A Case of Severe Frost Damage Prior to Budbreak in Young Conifers in Northeastern Ontario: Consequence of Climate Change? The Forestry Chronicle, 85, 453-462. http://dx.doi.org/10.5558/tfc85453-3

[12] Weiser, C.J. (1970) Cold Resistance and Injury in Woody Plants: Knowledge of Hardy Plant Adaptations to Freezing Stress May Help Us to Reduce Winter Damage. Science, 169, 1269-1278. http://dx.doi.org/10.1126/science.169.3952.1269

[13] Li, P.H. and Sakai, A. (1978) Plant Cold Hardiness and Freezing Stress. Academic Press, New York. 
[14] Colombo, S.J., Zhao, S.Y. and Blumwald, E. (1995) Frost Hardiness Gradients in Shoots and Roots of Picea mariana Seedlings. Scandinavian Journal of Forest Research, 10, 32-36.

[15] Hay, R.K.M. (1990) The Influence of Photoperiod on the Dry Matter Production of Grasses and Cereals. New Phytologist, 116, 233-254. http://dx.doi.org/10.1111/j.1469-8137.1990.tb04711.x

[16] Houlton, B.Z., Wang, Y.P., Vitousek, P.M. and Field, C.B. (2008) A Unifying Framework for Dinitrogen Fixation in the Terrestrial Biosphere. Nature, 454, 327-330. http://dx.doi.org/10.1038/nature07028

[17] Couteaux, M.M., Bottner, P. and Berg, B. (1995) Litter Decomposition, Climate and Liter Quality. Trends in Ecology \& Evolution, 10, 63-66. http://dx.doi.org/10.1016/S0169-5347(00)88978-8

[18] Robinson, C.H. (2002) Controls on Decomposition and Soil Nitrogen Availability at High Latitudes. Plant and Soil, 242, 65-81. http://dx.doi.org/10.1023/A:1019681606112

[19] Landis, T.D. (1989) Mineral Nutrients and Fertilization. In: Landis, T.D., Tinus, R.W., McDonald, S.E. and Barnett, J.P., Eds., The Container Tree Nursery Manual, Vol. 4, Department of Agriculture, Forest Service, Washington DC, 1-67.

[20] Miller, B.D. and Timmer, V.R. (1997) Nutrient Dynamics and Carbon Partitioning in Nutrient Loaded Picea mariana [Mill.] B.S.P. Seedlings during Hardening. Scandinavian Journal of Forest Research, 12, 122-129. http://dx.doi.org/10.1080/02827589709355393

[21] Puertolas, J., Gil, L. and Pardos, J.A. (2005) Effects of Nitrogen Fertilization and Temperature on Frost Hardiness of Aleppo Pine (Pinus halepensis Mill.) Seedlings Assessed by Chlorophyll Fluorescence. Forestry, 78, 501-511. http://dx.doi.org/10.1093/forestry/cpi055

[22] Bigras, F.J. and Bertrand, A. (2006) Responses of Picea mariana to Elevated $\mathrm{CO}_{2}$ Concentration during Growth, Cold Hardening and Dehardening: Phenology, Cold Tolerance, Photosynthesis and Growth. Tree Physiology, 26, 875-888. http://dx.doi.org/10.1093/treephys/26.7.875

[23] Norby, R.J., Warren, J.M., Iversen, C.M., Medlyn, B.E. and McMurtrie, R.E. (2010) $\mathrm{CO}_{2}$ Enhancement of Forest Productivity Constrained by Limited Nitrogen Availability. Proceedings of the National Academy of Sciences of the United States of America, 107, 19368-19373.

[24] D’Aoust, A.L. and Hubac, C. (1986) Phytochrome Action and Frost Hardening in Black Spruce Seedlings. Physiologia Plantarum, 67, 141-144. http://dx.doi.org/10.1111/j.1399-3054.1986.tb02435.x

[25] Bigras, F.J., Gonzalez, A., D’Aoust, A.L. and Hebert, C. (1996) Frost Hardiness, Bud Phenology and Growth of Containerized Picea mariana Seedlings Grown at Three Nitrogen Levels and Three Temperature Regimes. New Forests, 12, 243-259.

[26] Pearson, R.G. and Dawson, T.P. (2003) Predicting the Impacts of Climate Change on the Distribution of Species: Are Bioclimate Envelope Models Useful? Global Ecology and Biogeography, 12, 361-371. http://dx.doi.org/10.1046/j.1466-822X.2003.00042.x

[27] Astronomical Applications Department, U. S. Naval Observatory (2011) Table of Sunrise/Sunset for an Entire Year. http://aa.usno.navy.mil/data/docs/RS_OneYear.php

[28] Hijmans, R.J., Cameron, S.E., Parra, J.L., Jones, P.G. and Jarvis, A. (2005) Very High Resolution Interpolated Climate Surfaces for Global Land Areas. International Journal of Climatology, 25, 1965-1978. http://dx.doi.org/10.1002/joc.1276

[29] Bergeron, O., Lamhamedi, M.S., Margolis, H.A., Bernier, P.Y. and Stowe, D.C. (2004) Irrigation Control and Physiological Responses of Nursery-Grown Black Spruce Seedlings (1 + 0) Cultivated in Air-Slit Containers. HortScience, 39, 599-605.

[30] Colombo, S.J., Webb, D.P. and Glerum, C. (1984) Frost Hardiness Testing: An Operational Manual for Use with Extended Greenhouse Culture. Ontario Ministry of Natural Resources, Forest Research Report No. 110, 1-14.

[31] Colombo, S.J., Glerum, C. and Webb, D.P. (2003) Daylength, Temperature and Fertilization Effects on Desiccation Resistance, Cold Hardiness and Root Growth Potential of Picea mariana Seedlings. Annals of Forest Science, 60, 307-317. http://dx.doi.org/10.1051/forest:2003022

[32] DeLucia, E.H. and Thomas, R.B. (2000) Photosynthetic Responses to $\mathrm{CO}_{2}$ Enrichment of Four Hardwood Species in a Forest Understory. Oecologia, 122, 11-19. http://dx.doi.org/10.1007/PL00008827

[33] El Kohen, A. and Mousseau, M. (1994) Interactive Effects of Elevated $\mathrm{CO}_{2}$ and Mineral Nutrition on Growth and $\mathrm{CO}_{2}$ Exchange of Sweet Chestnut Seedlings (Castanea sativa). Tree Physiology, 14, 679-690. http://dx.doi.org/10.1093/treephys/14.7-8-9.679

[34] Norby, R.J. and Iversen, C.M. (2006) Nitrogen Uptake, Distribution, Turnover, and Efficiency of Use in a $\mathrm{CO}_{2}$-Enriched Sweetgum Forest. Ecology, 87, 5-14. http://dx.doi.org/10.1890/04-1950

[35] Yazaki, K., Ishida, S., Kawagishi, T., Fukatsu, E., Maruyama, Y., Kitao, M., Tobita, H., Koike, T. and Funada, T.R. 
(2004) Effects of Elevated $\mathrm{CO}_{2}$ Concentration on Growth, Annual Ring Structure and Photosynthesis in Larix kaempferi Seedlings. Tree Physiology, 24, 941-949. http://dx.doi.org/10.1093/treephys/24.9.941

[36] Zhang, S.R., Dang, Q.L. and Yu, X.G. (2006) Nutrient and $\left[\mathrm{CO}_{2}\right]$ Elevation Had Synergistic Effects on Biomass Production but Not on Biomass Allocation of White Birch Seedlings. Forest Ecology and Management, 234, $238-244$. http://dx.doi.org/10.1016/j.foreco.2006.07.017

[37] Wang, Z.M., Lechowicz, M.J. and Potvin, C. (1995) Responses of Black Spruce Seedlings to Simulated Present versus Future Seedbed Environments. Canadian Journal of Forest Research, 25, 545-554.

[38] Chapin III, F.S. (1980) The Mineral Nutrition of Wild Plants. Annual Review of Ecology and Systematics, 11, $233-260$. http://dx.doi.org/10.1146/annurev.es.11.110180.001313

[39] Guo, J.Y., Yang, Y., Wang, G.X., Yang, L.D. and Sun, X.Y. (2010) Ecophysiological Responses of Abies fabri Seedlings to Drought Stress and Nitrogen Supply. Physiologia Plantarum, 139, 335-347.

[40] Colombo, S.J., Glerum, C. and Webb, D.P. (1989) Winter Hardening in First-Year Black Spruce (Picea mariana) Seedlings. Physiologia Plantarum, 76, 1-9. http://dx.doi.org/10.1111/j.1399-3054.1989.tb05444.X

[41] Odlum, K.D. and Colombo, S.J. (1989) The Influence of Night Temperature under Declining Photoperiod on Bud Initiation in Black Spruce Seedlings. Canadian Journal of Forest Research, 19, 274-275. http://dx.doi.org/10.1139/x89-039

[42] Colombo, S.J. and Templeton, C.W.G. (2006) Bud and Crown Architecture of White Spruce and Black Spruce. Trees, 20, 633-641. http://dx.doi.org/10.1007/s00468-006-0078-y

[43] Krause, G. and Weis, E. (1984) Chlorophyll Fluorescence as a Tool in Plant Physiology. Photosynthesis Research, 5, 139-157. http://dx.doi.org/10.1007/BF00028527

[44] Krause, G.H., Somersalo, S., Osmond, C.B., Briantais, J.M. and Schreiber, U. (1989) Fluorescence as a Tool in Photosynthesis Research: Application in Studies of Photoinhibition, Cold Acclimation and Freezing Stress [and Discussion]. Philosophical Transactions of the Royal Society B: Biological Sciences, 323, 281-293. http://dx.doi.org/10.1098/rstb.1989.0010

[45] Rikala, R. and Repo, T. (1997) The Effect of Late Summer Fertilization on the Frost Hardening of Second-Year Scots Pine Seedlings. New Forests, 14, 33-44. http://dx.doi.org/10.1023/A:1006505919556 
Scientific Research Publishing (SCIRP) is one of the largest Open Access journal publishers. It is currently publishing more than 200 open access, online, peer-reviewed journals covering a wide range of academic disciplines. SCIRP serves the worldwide academic communities and contributes to the progress and application of science with its publication.

Other selected journals from SCIRP are listed as below. Submit your manuscript to us via either submit@scirp.org or Online Submission Portal.
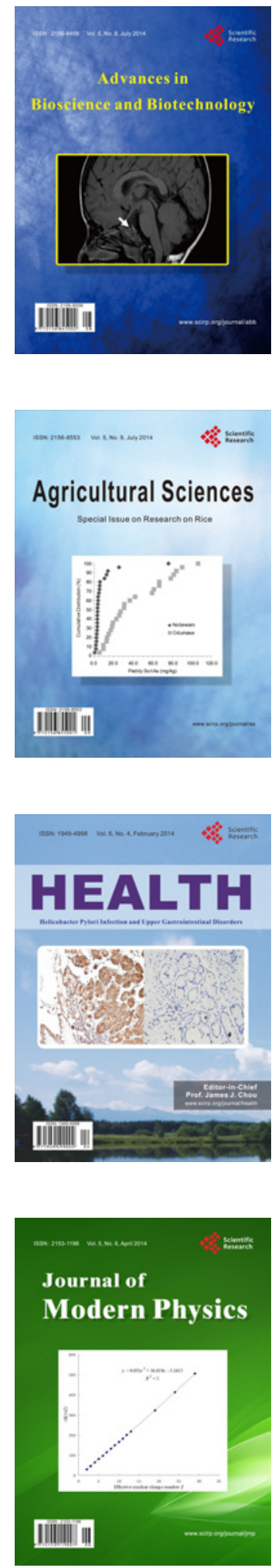
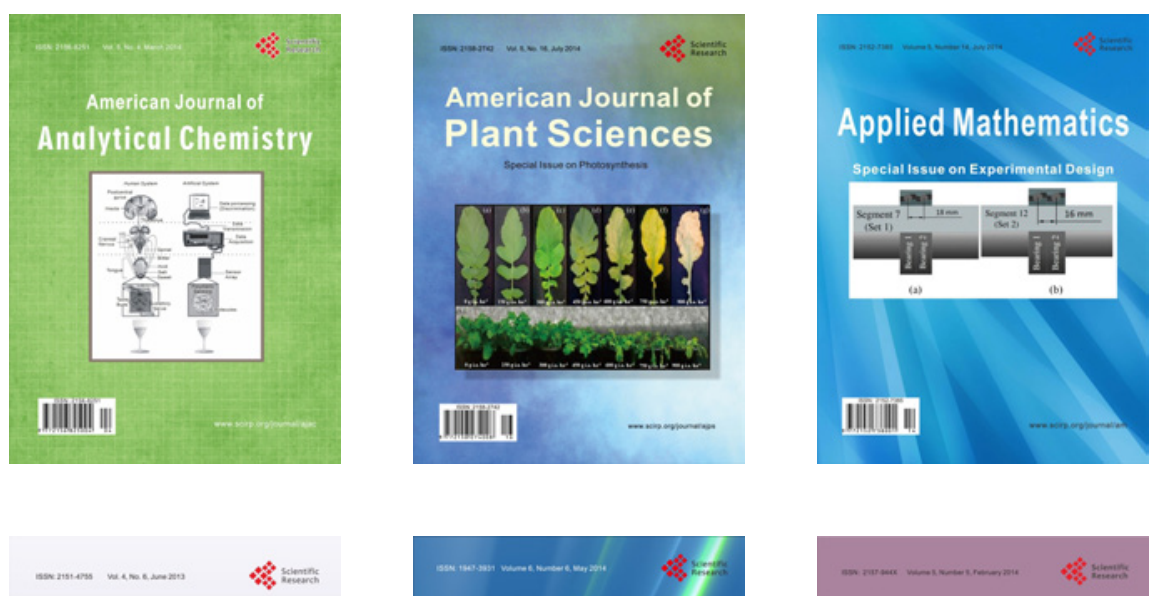

Creative Education
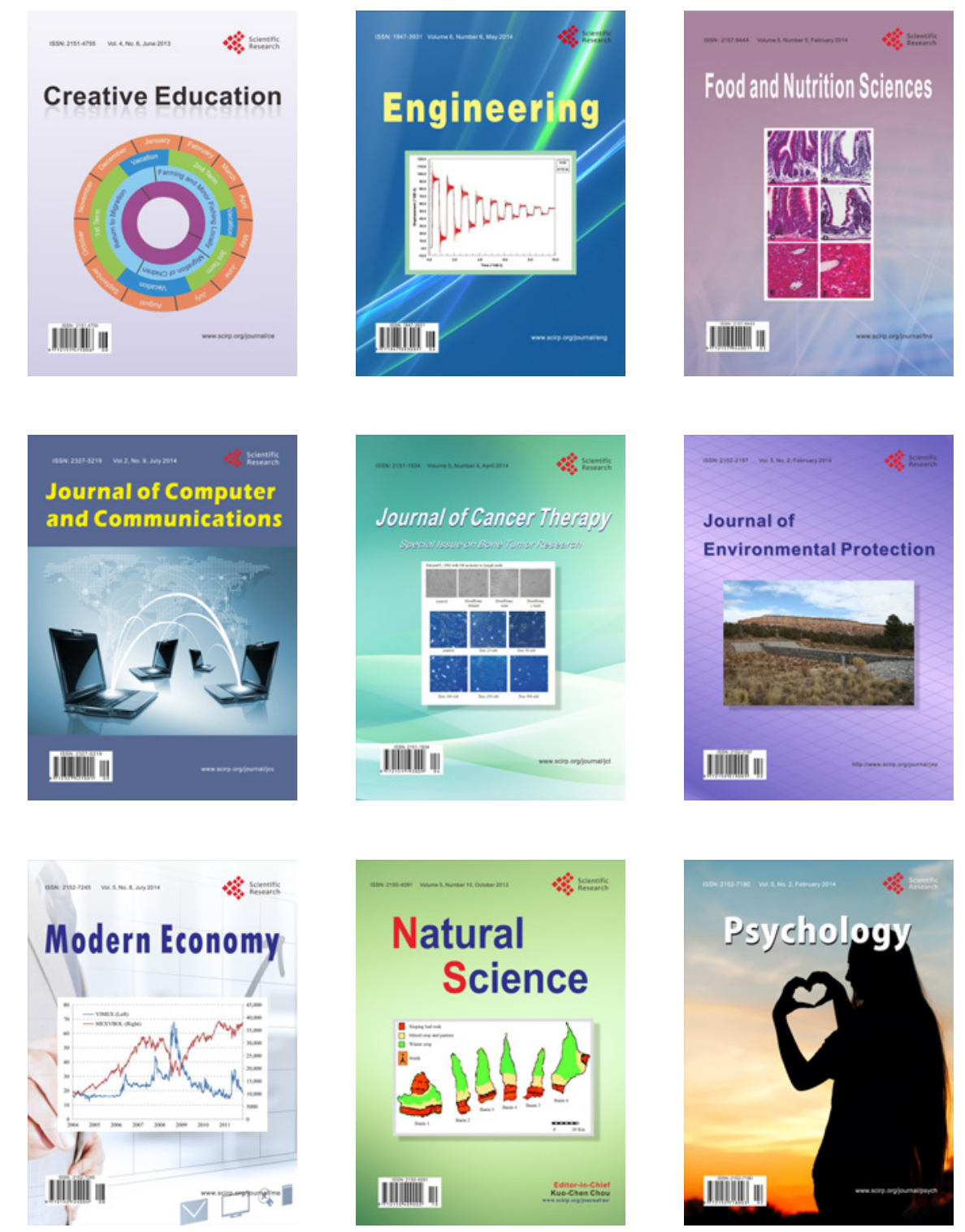